\title{
Vertebral fractures in steroid dependent asthma and involutional osteoporosis: a comparative study
}

\author{
Maite Luengo, Cesar Picado, Luis Del Rio, Nuria Guañabens, Josep M Montserrat, \\ Jorge Setoain
}

\begin{abstract}
Background Reduced bone mass predisposes patients to the development of vertebral fractures. Measurement of bone mass by non-invasive methods is used to detect patients with involutional osteoporosis at risk from fractures. These methods have not been assessed in patients with steroid dependent osteoporosis. The objective of this study was to assess the value of a predictive fracture threshold value of bone density in patients with steroid dependent asthma.

Methods Three groups of patients were studied. Group 1 (67 patients) had steroid dependent asthma (mean daily dose of prednisone $11.7 \mathrm{mg}$ ) and no vertebral fractures, group 2 (32 patients) had steroid dependent asthma (mean daily dose of prednisone $12 \mathrm{mg}$ ) and vertebral fractures, and group 3 (55 patients) were not taking steroids but had involutional osteoporosis and a recent non-traumatic vertebral fracture. Bone mineral density was measured by dual photon absorptiometry and vertebral fractures by radiography of the lumbar spine. A fracture threshold was determined in the two groups with fractures as the 90th percentile of the mean bone mineral density measured in the lumbar spine.
\end{abstract}

Results Bone mineral density was significantly higher in the steroid dependent group with fractures (group 2) than in group 3 patients, who had involutional osteoporosis and fractures $(0.946(0 \cdot 18) \mathrm{g} /$ $\left.\mathrm{cm}^{2} v 0.830(0 \cdot 16) \mathrm{g} / \mathrm{cm}^{2}\right)$. The fracture threshold value was therefore higher for patients with steroid related vertebral fractures (group $2,1 \cdot 173 \mathrm{~g} / \mathrm{cm}^{2}$ ) than for those with involutional osteoporosis (group 3, $0.979 \mathrm{~g} / \mathrm{cm}^{2}$ ). Vertebral fractures were more likely to occur in steroid dependent asthmatic patients with bone density above the fracture threshold value (obtained from subjects with involutional osteoporosis) than in subjects in group $3(34 \% v 9 \%)$.

Conclusion Vertebral fractures occur in patients treated with steroids in the presence of higher bone mineral density than is the case with patients with involutional osteoporosis. The findings suggests that the assessment of the efficacy of preventive treatment requires measurement of bone mineral density and radiology.
Although the mechanisms underlying steroid induced vertebral fractures are probably complex, a reduced bone mass (osteopenia) is usually considered an important contributory factor. ${ }^{1}$ Not all patients having regular oral steroid treatment develop vertebral fractures, however, ${ }^{2}$ and other factors, such as nutrition, exercise, exposure to sun, and hormone concentrations may interact with corticosteroids and modulate their effects on bone metabolism. $^{3}$ In recent years new and promising drugs, such as the biphosphonates ${ }^{4}$ and calcitonin, ${ }^{5}$ have been shown to prevent steroid induced osteoporosis. These treatments are expensive and frequently have side effects; thus any measure designed to prevent osteoporosis should be limited to those patients at increased risk of developing this complication.

During the last decade several procedures have been introduced to measure bone mass by non-invasive methods. ${ }^{6}$ Dual photon absorptiometry and quantitative computed tomography are the techniques used most commonly to measure bone mineral density, and an inverse relation between bone mineral density and risk of fracture has been found in subjects with involutional osteopenia. ${ }^{7}$ The bone mineral density below which the risk of fracture is increased has been defined as the fracture threshold value. ${ }^{8}$ This index depends on the absolute bone mineral density value and is independent of age and sex. ${ }^{7}$ With increasing age, however, an increased number of normal people fall below the fracture threshold. The validity of this index is supported by studies in patients known to have compression fractures. ${ }^{7}$ Determination of the fracture threshold value by non-invasive procedures may help in the early detection of patients with steroid dependent asthma who are at risk of developing vertebral fractures. Although a recent report ${ }^{9}$ suggested that measurement of bone mass is indicated for patients receiving long term glucocorticoid treatment, there are insufficient data at present to justify the use of these methods in managing steroid dependent osteoporosis. The usefulness of bone mass measurements in involutional osteoporosis is well documented, but the mechanisms underlying involutional osteoporosis may differ from those responsible for steroid related osteoporosis. The aim of this study was to establish the prevalence of vertebral fractures in a large population of steroid dependent asthmatic patients and to compare the bone mineral density of patients with asthma without (group 1) and with frac- 
tures (group 2) with that of a group of patients with involutional osteoporosis and fractures (group 3). The value of the vertebral fracture threshold obtained from group 3 in predicting fractures in group 2 was also determined.

\section{Methods}

POPULATION

Ninety nine consecutive adults with asthma who were dependent on oral corticosteroids and who were seen in the outpatient clinic were included in the study. Asthma was diagnosed when there was a history of shortness of breath, wheezing, and evidence of reversible airway obstruction. Patients with clinical symptoms, radiological changes, or lung function abnormalities suggesting obstructive bronchial disease other than asthma, such as chronic bronchitis, bronchiectasis, and emphysema, were excluded. Only patients who were taking oral corticosteroids daily were admitted. None of the subjects had clinical symptoms or signs to suggest that they had a disease that might be responsible for osteoporosis. Patients with known alcohol abuse or taking medications known to cause alterations in bone mineral, such as oestrogens, androgens, fluoride, vitamin D, diuretics, and anticonvulsivants, were excluded. The characteristics of the subjects are shown in the table.

The study compared the asthmatic patients with fractures (group 2) with subjects with a recent non-traumatic vertebral fracture of the thoracic spine confirmed by bone scintigraphy (group 3). This group was composed of 55 consecutive subjects referred to the laboratory of nuclear medicine for evaluation of bone mineral density. None of these patients was taking any medication or was known to have a disease potentially responsible for osteoporosis. Patients with fractures affecting the

Characteristics of the asthmatic patients and control group (mean (SD) values)

\begin{tabular}{|c|c|c|c|}
\hline & $\begin{array}{l}\text { Group 1: steroid } \\
\text { dependent asthma } \\
\text { without fractures } \\
(n=67)\end{array}$ & $\begin{array}{l}\text { Group 2: steroid } \\
\text { dependent asthma } \\
\text { with fractures } \\
(n=32)\end{array}$ & $\begin{array}{l}\text { Group 3: } \\
\text { involutional } \\
\text { osteoporosis } \\
\text { (control) }(n=55)\end{array}$ \\
\hline \multirow{8}{*}{$\begin{array}{l}\text { Age }(y) \\
\text { Sex }(M / F) \\
\text { Mean steroid dose } \\
\text { (mg/day) } \\
\text { Duration of steroid } \\
\text { treatment }(y) \\
\text { Beclomethasone } \\
(\mu \mathrm{g} / \text { day }) \\
\text { Bone mineral density } \\
\left(\mathbf{g} / \mathrm{cm}^{2}\right) \\
(\% \text { of value predicted } \\
\text { for age })\end{array}$} & $53.6(11.8) \dagger$ & $58.3(9 \cdot 4)$ & $63.4(10.8) \dagger$ \\
\hline & & $10 / 22$ & $15 / 40$ \\
\hline & $11.7(5.4)$ & $12(5 \cdot 1)$ & - \\
\hline & & & \\
\hline & $8 \cdot 3(6 \cdot 2)$ & $9 \cdot 9(7 \cdot 4)$ & - \\
\hline & $590(240)$ & $645(250)$ & - \\
\hline & $1.044(0 \cdot 18) \ddagger$ & $0.946(0.18) \ddagger \S$ & $0.830(0.16) \S \ddagger$ \\
\hline & $91.8(13.4)^{\star \star}$ & $85 \cdot 8(13)$ & $81 \cdot 3(11 \cdot 7)^{\star \star}$ \\
\hline
\end{tabular}

*Expressed as mg prednisone equivalent/day.

$\dagger$ The steroid dependent group without fractures were younger than the control group ( $p \leqslant 0.05$, one way analysis of variance and Sheffè's contrast).

$\ddagger$ Bone mineral density expressed as $\mathrm{g} / \mathrm{cm}^{2}$ was significantly lower in the control group with respect to both the steroid dependent group with fractures $(p \leqslant 0.05)$ and the steroid dependent group without fractures (for both $p \leqslant 0.05$, one way ANOVA and Sheffè's contrast).

$\star \star$ Bone mineral density expressed as a percentage of the value for age was significantly lower in the control group than in the steroid dependent group without fractures. second, third, and fourth lumbar vertebrae were exluded to prevent errors in the measurement of bone mineral density. None of the patients had had prolonged immobilisation as a consequence of back pain.

\section{RADIOLOGICAL STUDY}

Radiographs of the thoracic and lumbar spine in two projections were obtained from all patients with asthma. Deformities of vertebral bodies suggesting fractures were divided into three groups-wedge, biconcave, and crush fractures. Wedge fractures were defined as a reduction of $25 \%$ or more in the anterior height and bioconcave fractures in the middle height of the vertebrae. A crush fracture was diagnosed when the posterior height of the vertebra was less than $15 \%$ of the posterior height of an adjacent vertebra. ${ }^{10}$ Radiological evaluation was carried out by an experienced observer who was blind to the details of the patients.

BONE MINERAL MASS AND FRACTURE THRESHOLD The bone mineral density of the lumbar spine was measured by dual photon absorptiometry with the Lunar Radiation Corporation scanner DP3 (Madison, Wisconsin, USA). The scanner uses a gadolinium-153 source showing photopeaks at 44 and $100 \mathrm{KeV}$. Bone mineral density values were obtained from the lumbar vertebrae L2, L3, and L4 and expressed in terms of $\mathrm{g} / \mathrm{cm}^{2}$. Forty scan lines, $4.5 \mathrm{~mm}$ apart, were obtained with a transverse speed of $5 \mathrm{~mm} / \mathrm{s}$. Counts were obtained every 0.5 second. The coefficient of variation in vitro, calculated with daily phantom studies $(\mathrm{n}=300)$ collected over one year, was $0.51 \%$. The coefficient of variation in vivo was $1.37 \%$ in healthy young subjects and $2.7 \%$ in patients with osteoporosis. These data were obtained from 10 normal volunteers and five osteoporotic patients measured weekly for five weeks.

Predicted bone mineral mass values were obtained from 547 healthy women and 328 healthy men (unpublished observations).

The 90th percentile of the mean bone mineral density in the lumbar spine (L2, L3, L4) was chosen as the fracture threshold (the value below which the risk of non-traumatic vertebral fracture increases). ${ }^{11}$

\section{ANALYSIS}

Statistically significant differences between sets of data from the three groups were assessed by means of one way analysis of variance and Sheffè's contrasts. Differences in the characteristics of treatment between patients with asthma with and without fractures were analysed with two tailed $t$ tests for unpaired variables. The relation between bone mineral density and corticosteroid treatment (mean daily dose of prednisone and duration of treatment) was assessed by using Pearson's correlation. The prevalence of vertebral fractures when the bone mineral density was at or above the fracture threshold value was compared in patients with asthma and in patients with involutional osteoporosis by means of the $\chi^{2}$ test. A probability value of 0.05 was considered significant. 


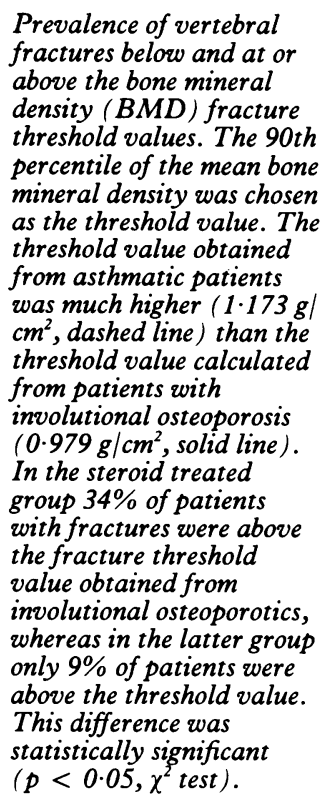

\section{BMD}

$\left(\mathrm{g} / \mathrm{cm}^{2}\right)$

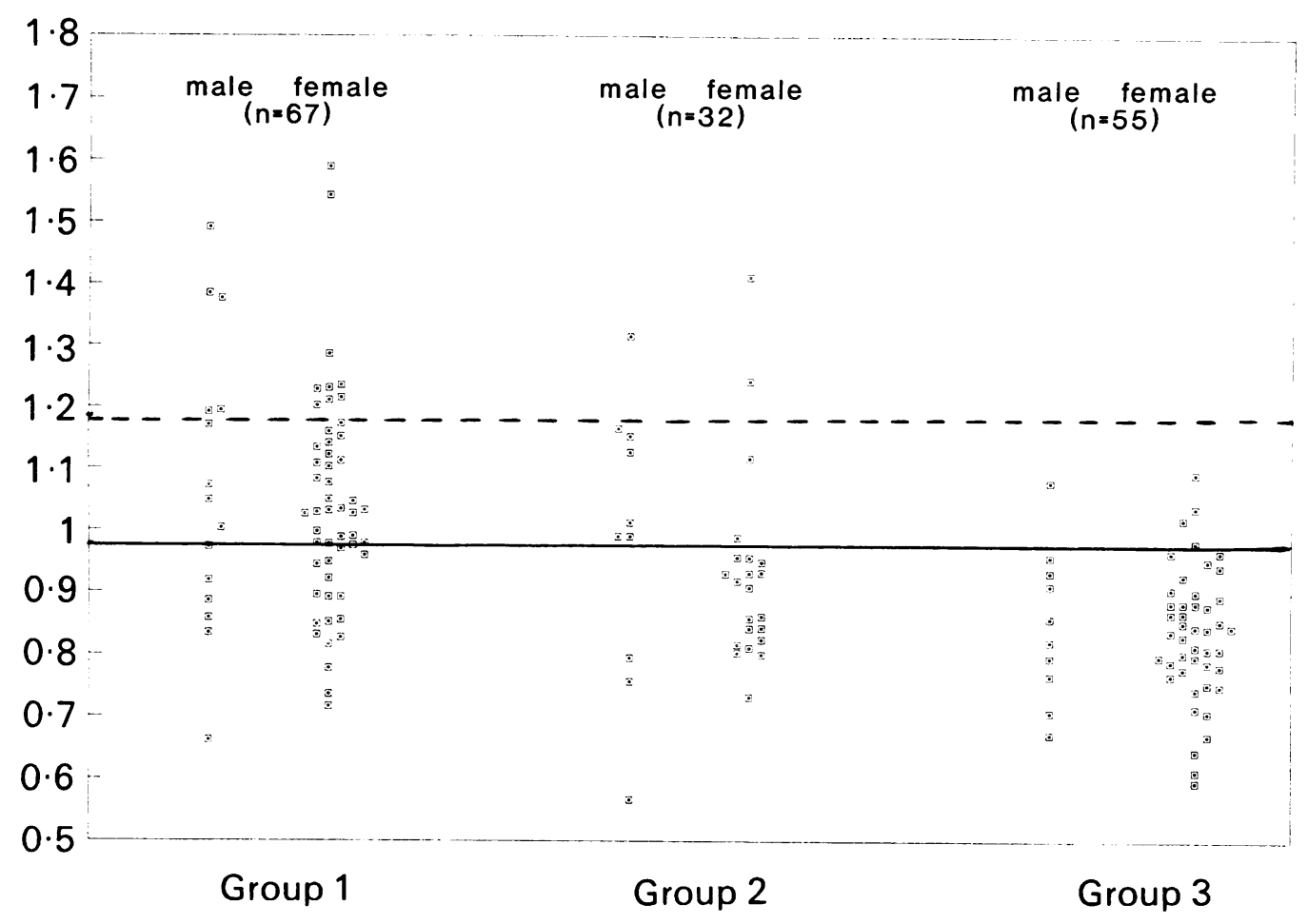

\section{Results}

POPULATION

The characteristics of the three groups are given in the table. Patients with corticosteroid treated asthma without fractures (group 1) were younger than those with involutional osteoporosis (group 3$)(p<0.05)$. The mean daily dose of prednisone in the two groups of asthmatic patients $(11.7 v 12.0 \mathrm{mg})$ and the duration of steroid treatment $(8.3$ and 9.9 years) were similar. The mean dose of beclomethasone was also similar in the two groups of asthmatic patients.

\section{PREVALENCE OF FRACTURES}

The prevalence of vertebral fractures in the thoracic and lumbar spine in patients with steroid dependent asthma was $34 \%$. The 32 patients with steroid dependent asthma and vertebral fractures had 95 fractures altogether (range 1-10), 83 in the thoracic and 12 in the lumbar spine (none of these fractures affected L2, L3, or L4 vertebrae); $66 \%$ were wedge, $18 \%$ biconcave, and $18 \%$ crush fractures.

\section{BONE MINERAL DENSITY}

Bone mineral density was significantly lower in patients with involutional osteoporosis than in patients with asthma with and without fractures $(p<0.05)$. Although the bone mineral density of the patients with steroid dependent asthma who had vertebral fractures (group 2) was lower than in those without fractures (group 1), the difference did not reach statistical significance. Bone mineral density expressed as a percentage of predicted aged matched values was lower in subjects with involutional osteoporosis (group 3) than in either group of asthmatic patients, but the difference was significant only for the group without fractures, group 1 ( $p<0.05$ : table). length of treatment, with the average daily steroid dose, or with the cumulative dose of corticosteroids (mean daily dose times years of treatment).

VERTEBRAL FRACTURES AND BONE MINERAL DENSITY FRACTURE THRESHOLD VALUE

Bone mineral density values for the three groups and the threshold vertebral fracture value for the subjects with fractures (patients with asthma and with involutional osteoporosis) are shown in the figure. The fracture threshold value for the asthmatic patients (group 2: $1.173 \mathrm{~g} / \mathrm{cm}^{2}$ ) was much higher than the value obtained from the patients with involutional osteoporosis (group 3: $0.979 \mathrm{~g}$ / $\mathrm{cm}^{2}$ ). In the steroid treated group (group 2) 11 of 32 patients with fractures had a bone mineral density at or above the fracture threshold value obtained from the patients with involutional osteoporosis (group 3: five of $56(9 \%)$ ). This difference was significant $(p \leqslant 0.05)$. The spine radiographs showed no abnormality (osteophytosis, lumbar hyperostosis, or aortic calcification) that might cause misinterpretation of bone mineral density in the 11 patients with asthma and fractures and with bone mineral density values at or above the fracture threshold value.

\section{Discussion}

Our study shows that the predictive value of bone mineral density measurements in patients
Bone mineral density was not correlated with 
with involutional osteporosis cannot be extrapolated to steroid induced osteoporosis, and suggests that the mechanisms underlying the two diseases differ considerably. Many steroid dependent patients, in contrast to those with involutional osteoporosis, developed vertebral fractures despite having a normal bone mineral density. Thus vertebral fractures in patients with asthma taking regular oral corticosteroids seem to be the consequence of a complex mechanism including decreased bone mass as well as an increased fragility of the bones. Possibly asthmatic patients had more vertebral fractures above the fracture threshold as a consequence of severe coughing. Vertebral fractures, however, are not more prevalent in those with a current cough, such as patients with chronic bronchitis, than in healthy people, suggesting that coughing in itself cannot account for vertebral fractures in bronchial asthma. ${ }^{12}$ If cough causes vertebral fractures, the bone must presumably be abnormal also.

Bone loss is the result of both increased resorption and reduced bone formation. ${ }^{13}$ The accelerated destruction is usually considered to be the consequence of secondary hyperparathyroidism due to reduced intestinal calcium absorption, but a direct effect of corticosteroids on bone resorption and formation cannot be excluded..$^{14} \mathrm{~A}$ direct deleterious effect of corticosteroids on the bone architecture or the collagen matrix, or both, might account for the accentuated vertebral weakness in patients with an otherwise normal bone mass. ${ }^{15} \mathrm{His}-$ tomorphometric studies of bone biopsy material show many alterations that might explain the accentuated vertebral weakness of these patients. A decrease in the amount of bone, bone forming surfaces, and protein synthesis are some of the effects of corticosteroids that are likely to play a part in corticosteroid induced vertebral fractures. ${ }^{16}$ In a recent experiment Ortoft and Oxlund ${ }^{17}$ found a reduction in bone strength in the femora of rats treated with low doses of glucocorticoids. This reduction was found after correction for the decreased thickness of cortical bone, indicating that the reduction in bone strength induced by glucocorticoids is caused by a reduction in bone quality in addition to a decrease in bone quantity. The importance of the direct effects of steroids on bone architecture may account for the lack of efficacy of prophylactic treatments designed to increase bone mineral mass, such as calcium supplementation ${ }^{18}$ and vitamin D treatment. ${ }^{13}$ These poor results contrast with the positive effects obtained with agents that block bone resorption, such as calcitonin ${ }^{5}$ and bisphosphonates, ${ }^{4}$ and suggest that treatment that counteracts the direct effects of corticosteroids on bone resorption may be the most efficient preventive treatment for steroid induced osteoporosis.

Our study shows that osteoporosis is a frequent complication of steroid dependent asthma. It also suggests that the new methods for measuring bone mass, such as dual photon absorptiometry, are less useful for detecting patients at risk of developing vertebral fractures in corticosteroid induced osteoporosis than in involutional osteoporosis. This is probably because these methods detect changes in bone mass but not the effects of steroid treatment on bone architecture. Dual photon absorptiometry may be a useful monitor of loss of bone mass in patients having treatment with prolonged oral steroids, but the information must be complemented by standard radiographic studies. Predictive indices, such as the fracture threshold value for bone mineral density, cannot be extrapolated from individuals at risk of developing bone fractures due to other causes and must be specifically obtained from an asthmatic population. As dual photon absorptiometry measures only one effect of corticosteroids on bones, the efficacy of any new preventive treatment must be assessed on the basis of both bone bone mineral density and the incidence of new vertebral fractures.

This work was supported in part by a grant from the Fondo de Investigaciones Sanitarias.

1 Riggs BL, Melton LJ. Involutional osteoporosis. N Engl J Med 1986;314:1676-86.

2 Adinoff AD, Hollister JR. Steroid-induced fractures and bone loss in patients with asthma. N Engl J Med 1983; 309:265-8.

3 Pocock N, Eisman J, Gwinn T, Sambrook P, Kelly P, Freund J, Yeates $M$. Muscle strength, physical fitness, and weight but not age predict femoral neck bone mass. J Bone Mineral Res 1989;4:441-8.

4 Reid IR, King AR, Alexander CJ, Ibbertson HK. Prevention of steroid-induced osteoporosis with (3-amino-1hydroxypropylidene)-1,1-biphosphonate (ADP). Lancet $1988 ; \mathrm{i}: 143-6$.

5 Luengo M, Picado C, Del Rio L, Guañabens N, Montserrat JM, Setoain J. Treatment of steroid-induced osteopenia with calcitonin in corticosteroid-dependent astham. A one-year follow-up study. Am Rev Respir Dis 1990; 142:104-7.

6 Ott SM, Kilcoyne RF, Chesnut III CH. Ability of four different techniques of measuring bone mass to diagnose vertebral fractures in postmenopausal women. J Bone Mineral Res 1987;2:201-10.

7 Wahner HW. Single and dual photon absorptiometry in osteoporosis and osteomalacia. Semin Nucl Med 1987; 27:305-15.

8 Melton LF III, Riggs BL. Epidemiology of age-related fracture. In: Avioli LV, ed. The osteoporotic syndrome: detection, prevention and treatment. Orlando, Florida: Getection, prevention and treatment

9 Johnson CC, Melton LJ, Lindsay R, Eddy DM. Clinical indications for bone mass measurements. A report from the Scientific Advisory Board of the National Osteoporosis Foundation. J Bone Mineral Res 1989;4 (suppl 2):1-28.

10 Eastell R, Riggs BL. Diagnostic evaluation of osteoporosis. Endocrinol Metabl Clin North Am 1988;17:547-571.

11 Riggs BL, Wahner HW, Seeman E, Offord KP, Dunn WL. Changes in bone mineral density of the proximal femur and spine with aging. Differences between the postmenopausal and senile osteoporosis syndrome. J Clin Invest 1982;70:716-23.

12 Riancho JA, Gonzalez Macias J, del Arco C, Amado JA, Freijanes J, Antón MA. Vertebral compression fractures and mineral metabolism in chronic obstructive lung disease. Thorax 1987;42:962-6.

13 Lukert B, Raisz LG. Glucocorticoid-induced osteoporosis: pathogenesis and management. Ann Intern Med 1990; 112:352-64.

14 Peck WA. The effects of glucocorticoids on bone cell metabolism and function. Adv Exp Med 1984;171:111-9.

15 Heaney RP. Calcium, bone health and osteoporosis. In: Peck WA, ed. Bone mineral research: 4. Amsterdam: Elsevier, 1986:255-301.

16 Dempster DW, Arlot MA, Meunier PJ. Mean wall thickness and formation periods of trabecular bone packets in corticosteroid-induced osteoporosis. Calcif Tissue Int 1983;35:410-7

17 Ortoft G, Oxlund H. Reduced strength of rat cortical bone after glucocorticoid treatment. Calcif Tissue Int 1988; 43:376-82.

18 Reid IR, Ibbertson HK. Calcium supplements in the prevention of steroid-induced osteoporosis. Am J Clin Nutr 1986;44:287-90. 